\title{
Contribution of the project SIGMEA to ecological biosafety in GM maize, oilsed rape and beet
}

\author{
G. Squire \\ Scottish Crop Research Institute, Dundee, United Kingdom \\ Correspondence to: Prof. Dr. Geoffrey Squire, Scottish Crop Research Institute (SCRI), \\ Invergowrie, Dundee DD2 5DA, Scotland, United Kingdom, \\ Tel: +44 1382 562731, (switchboard), E-mail: geoff.squire@scri.ac.uk
}

The EU project SIGMEA mainly addressed issues in GM coexistence, but many of the data set contributed and analysed by around 22 partners also contained information relevant to the ecological impacts of GM maize (Bt), oilseed rape (HT) and beet. SIGMEA partners carried out some of the largest, most comprehensive and most long running GM crop trials in Europe and so are well placed to synthesise the current state of knowledge on ecolgical impacts. This presentation defines which effects are likely to occur and the size of adverse and beneficial effects (if any) relative to differences among other agricultural practices. It finally suggests improvements that might be made in ecological risk assessment.

A summary will be given of the approach and main findings on GM impacts from the EU SIGMEA project, which combined the findings and expertise from around 25 research organisations. The potential sources of impact - e.g. direct effect of GM organism, gene movement and persistence, associated management - will be considered for data from field experiments on (primarily) Bt maize and HT oilseed rape.

To access this journal online: http://www.birkhauser.ch/JVL 